\title{
A Psycholinguistic Justification of Dictation in TEM-4
}

\author{
Lianbing $\mathrm{Yao}^{1}$ \\ ${ }^{1}$ School of Foreign Languages, China West Normal University, Sichuan, China \\ Correspondence: School of Foreign Languages, China West Normal University, No. 1 Shi Da Road, Nanchong \\ 637009, Sichuan, China. Tel: 86-817-259-6394. E-mail: lbyao115@163.com
}

\author{
Received: May 04, 2013 Accepted: June 1, 2013 Online Published: July 17, 2013 \\ doi:10.5539/ijel.v3n4p101 URL: http://dx.doi.org/10.5539/ijel.v3n4p101
}

The research is financed by Department of Education of Sichuan Province (Project No. SCWY12-18), China West Normal University (Project No. 12B027), and the Center for Translation and Research of Chinese Culture and Literature.

\begin{abstract}
Dictation is an important way to check the examinees' language competence. To examine the examinee in this way, there must be some theoretical basis, and to prepare for it, there must also be some ways. This essay tries to look into the issue from the previous two aspects. We especially borrow the theories in psycholinguistics in dealing with the justification of dictation in TEM-4.
\end{abstract}

Keywords: dictation, error analysis, TEM-4, language competence

\section{Introduction}

Dictation finds its appearance in TEM-4 (test for English majors-band 4) in 1990 in China. As is pointed out by Brown \& Barnard, to take dictation requires a lot of skills, and this test form can be used to train students' ears. It can also be used to train their writing skills and short-term memory of the sequence of the sentences(Carroll, 2000 , p. 52). Ong also thinks that dictation can be used to help the learners to get familiar with the grammar of the target language, and it helps to enhance their writing competence(Carroll, 2000, p. 55). The style of the material to be copied is usually of all kinds, and the length is always within 150 words. In the exam, the essay is read four times: for the first reading, the essay is read at normal speed and the students are required to listen to understand the material; for the second and the third readings, the material is read slowly with intervals of 15 to 20 seconds, and students are supposed to copy down the text; for the fourth reading, the essay is read at normal speed again for the students to check. Finally, students are given 2 more minutes to have an overall understanding of the passage to make it as accurate as what is read. Students supposed to take the exam are the second year English majors in the second semester.

The initial purpose of TEM-4 is to check whether all the requirements have been met by the students after they have finished studying all the courses at the elementary stage of English study, and to see whether they have mastered all the basic skills required on the part of the English majors. (Team, 2004, p. 3)In practice, dictation tries to test the two skills: receptive skills and productive skills .

Except all these, the test is designed to see how much the second year English majors know about the English grammar and vocabulary. From the results of all these, teachers can have an all-round understanding of their students' comprehensive knowledge of English and the knowledge. Yet, from the outcomes of the test during the recent years, the conclusion can be made that dictation is a difficult part in TEM-4 for the English majors, and it is effort-consuming for the teachers to help their students to make some improvement in this part. At the same time, the results of this part during the recent years show that many students did a poor job, and some of them even got zero. Also, the national average score for this year is 7.02, and the national average score of the English majors at normal universities is 8.09 (the passing score is 9). Therefore, attention should be paid to this part, and this essay is aimed to find the theoretical basis of the test, to analyze the errors in taking this part, and to provide some suggestions for the English majors and their teachers.

\section{Psycholinguistic Process Involved in Taking the Test}

In taking the test, students would theoretically undergo the following stages: expectation, speech perception, taking words out of their mental lexicon, sentence comprehension and memory, discourse comprehension and 
memory, and spelling. On the very first stage, students should mentally get ready for the coming test, i.e., they have to stimulate all their understanding concerning how to take the exam, the skills they have gained on how to do it, and the words that might appear in the exam. The reason why the examiners give the topic or the title of the passage on the paper is that the examinees are supposed to gather the related words from their mental lexicon beforehand. On the second stage, there comes the important step in the course of dictation: the input of the information. This process is the process of bottom-up for the examinee. Speech perception is quite difficult because of the inherent variability of speech sounds and the phonological context and other speech sounds in the environment. On the third stage, the students come to the most important and the most difficult point. This part plays a decisive role in the course of dictation since it determines whether the students can understand the essay and whether they can jot it down . Here the working memory is the busiest because on the one hand, it will receive the auditory information and try to understand it. On the other hand, it also tries to memorize the sentence so as to write it down later. Yet, the point is that the working memory is quite limited in size. It connects the sensory stores, permanent memory, and the control processes as the following table shows:

\begin{tabular}{|l|l|l|l|l|}
\hline & sensory stores & working memory & $\begin{array}{l}\text { permanent } \\
\text { memory }\end{array}$ & control processes \\
\hline $\begin{array}{l}\text { environmental } \\
\text { stimuli }\end{array}$ & $\begin{array}{l}\text { visual, auditory, } \\
\text { etc. }\end{array}$ & $\begin{array}{l}\text { current goals, } \\
\text { consciousness, } \\
\text { etc. }\end{array}$ & $\begin{array}{l}\text { knowledge, skill, } \\
\text { beliefs, etc. }\end{array}$ & $\begin{array}{l}\text { plans, strategies, } \\
\text { etc. }\end{array}$ \\
\hline
\end{tabular}

Figure 1. A general model of information processing (Carroll, 2000, p. 47)

On the fourth stage and the fifth stage, the students will have to finish another decisive step since this one will give the examinees the global understanding of the text. Later on it will help to give them the discourse context for them to form the semantic and syntactic structure. Also, the memory of the text will help the students to take the top-down approach when they come to check their writing. On the sixth stage, which is also the productive stage, the students will put what they have got from the material onto paper. At this time, the students will make the best use of their working memory and permanent memory with the help of their automatic and controlled processes.

\section{Students' Problems in Taking Dictation}

From the outcomes of the test, there are mainly the following types of problems, or errors the students might meet with in the exam:

\section{A. Deletion of words}

Among the 60 students in the examination, about $65 \%$ have experienced this kind of mistake. The words being deleted are articles, prepositions, adverbs, and the pronouns. Except the deletion of words, there also exist the deletion of such affixes as -ing, -ed, -s, -es, and so on.

\section{B. Misspelling of words}

As transferors of pronunciation, the English words also indicate the information of meanings. Therefore, if the English words are misspelled, the meanings will also be changed. The survey shows that a large number of students commit this kind of mistake. Carefully examined, the mistake can be classified into the following two types according to the ways they are committed: sound deviation and graphemic substitution.

\section{a. Sound deviation}

This sort of error is made by the students for the reason that part of the words deviate from the normal ones, for example, addition of sounds, deletion of sounds, replacement of sounds, misplacement of sounds. Among all the four kinds of errors, the first two amount to $60 \%$. Addition of sounds appears when students add the unnecessary suffixes $-\mathrm{s}$, -es to the singular nouns. For instance, a three-day wait is written as a three-days wait; thing is misspelled as things; sort is replaced by sorts, etc. Some students even add some letters to the words, for example, sort is changed into sourt; forty into fourty, and so on. Besides, some students add the unnecessary suffixes -s, -es, -ed to the verbs.

Compared with the deletion of sound, intrusion of sound is more common. For example, there is written as the; another as other; backward as back; its as it, etc.

Replacement of sounds means some of the words are replaced by those sharing the similar sounds. Cases in point are vary and very; consent and content; sort and thought; complexities and complecities or complexity. 
Misplacement of sounds refers to some morpheme or letter in the words are misplaced in written. Just like some students spell residents as risedents; ceremony as cemerony, and so on.

Among the four forms of sound deviation, deletion of sounds enjoys the highest frequency, followed by intrusion of sound, replacement of sounds, and misplacement of sounds.

\section{b. Graphemic substitution}

This sort of error occurs when the wrong words share the same pronunciations with the original ones, but the meanings expressed by the wrong words differ from the correct ones. Examined carefully, this type of mistake takes the following forms as the chart shows:

\begin{tabular}{|l|l|l|l|l|}
\hline correct words & $\begin{array}{l}\text { misspelled } \\
\text { words }\end{array}$ & error type & frequency & percentage \\
\hline shows & shoes & replacement & 6 & 10 \\
\hline know & no & replacement & 6 & 10 \\
\hline legal & legale & mute letters & 3 & 5 \\
\hline primitive & primitiv & intrusion & 3 & 5 \\
\hline requirement & requirment & mute letters & 8 & 13.3 \\
\hline language & langage & deletion of letters & 8 & 13.3 \\
\hline difference & diferrence & misspelled double letters & 2 & 3.33 \\
\hline
\end{tabular}

Figure 2. Error analysis of graphemic substitution (Sheng, 2003, p. 54)

For this kind of mistake, some are made because students are not familiar with the words, or because they are not so certain about the spellings of them. But since they are required to jot down those words, they have to spell "them" out according to their pronunciations. Some of the misspelled words do not exist, therefore, this kind of mistake is also called coinage spelling mistake by some linguists. For example, such words like primitiv, requirment, diferrence, and so on do not exist in the present English dictionaries.

\section{Overturned word order}

This type of error often happens within a sentence when the order of the adjacent words is changed by the students. For instance, the original phrase both females and males is change into both males and females; "Most states, for instance, have a...." is changed into "For instance, most states have a...". Among all the examinee, about $30 \%$ of them make this sort of mistake.

\section{Capitalization and punctuation}

During the process of dictation, a lot of students (about 75\%) always forget to capitalize the beginning letters of sentences or the proper nouns. The same is true of punctuations as indicated in the following table:

\begin{tabular}{|l|l|l|l|l|}
\hline type & original item & wrong item & $\begin{array}{l}\text { persons making } \\
\text { the mistake }\end{array}$ & percentage \\
\hline full stop(.) & $\ldots$.remain so. & $\ldots$ remain so, & 24 & 40 \\
\hline capitalization & However, & however, & 24 & 40 \\
\hline comma(, $)$ & $\begin{array}{l}\text { However, } \\
\text { parents... }\end{array}$ & However parents... & 36 & 60 \\
\hline colon(:) & $\ldots$ adequate: each & $\begin{array}{l}\text {...adequate, each; } \\
\text {...adequate. Each }\end{array}$ & 48 & 80 \\
\hline hyphen(-) & blood-test & blood test & 42 & 70 \\
\hline possessive case & parents' & parents & 40 & 66.7 \\
\hline
\end{tabular}

Figure 3. Common mistakes of punctuations (Sheng, 2003, p. 55) 


\section{E. Ambiguity of concept schema}

In practice, because of the ambiguity of concept schema, such semantic errors as distortion of sequences, distortion of forms, deletion, and intrusion might appear. During the first reading, since some students cannot understand the material, they will try to finish writing the sentences according to their own understanding or experience; thus distortion of meaning occurs. For example, in 1996, there is one sentence like this:

E-A Among the Indians of north America the medicine man was a very important person.

Because many students did not make the best use of the bottom-up process, their productive skill couldn't come to the full play. Therefore, many students wrote the sentence in the following ways:

E-A-1 Among the India of north American the medicine mum is a very important person.

E-A-2 A mountain Indians of north American the medicine mother was a very important person.

E-A-3 Among the Indias of northern America the max man was a very important person.

E-A-4 Among the Indians of north-America the mighty man was a very important person.

E-A-5 Among the Indians of north America the mad man was a very important person.

These mistakes are made mainly because the students are not so familiar with the concept schemata of some words or phrases. Hence, the distortion of forms and meanings will appear.

\section{F. Grammatical mistakes}

Because the students are not familiar with some expressions in English, they are likely to make a certain grammatical mistake like agreement between subject and predicate, part of speech, prepositional phrase, sentence structure, and conjunctions. For example, in TEM-4 in 1998, there is one sentence like this: The need to run the railway on time meant the local time was abolished. The word underlined is misspelled into mean, meaned, mend, made, moment, ment, met, etc. One more example is that in 1994, the underlined phrase in the expression "With the divorce rate nearly one in two, ..." is changed into one or two, one in too, only two, while into, and so on.

\section{G. Spelling mistakes}

Where there are words not included in the vocabulary for TEM-4, for example, aviation, diverse, supernatural, and so on, there exist the spelling mistakes. If there are proper nouns (like Victorian, Indian, etc) and poly-syllabic words which are difficult to identify (like fantastic, available, kilometers, etc), there also exist spelling mistakes.

\section{Suggested Solutions to the Problems}

From the results and the problems in TEM-4, we can see attention should be paid to the following: pronunciation, spelling, and meaning. The dictation in TEM-4 happens to test the three altogether. Therefore, the teachers and their students should pay their dual attention to each of them.

A. Many students cannot do this part satisfactorily mainly because they cannot understand the passage. The implied reason for this is that their own pronunciations do not go with those of the speakers on the tape. Psychologically speaking, it is because they cannot take the pronunciations out of their permanent memory to match the ones on the tape--problem coming from the process of top-down. Even if they can do it finally, it will take them quite a long time. Yet, the tape will not wait for them. In the end, they have to hurry up to catch the tape at the cost of the understanding of the passage. From this aspect, we suggest that on the one hand, we teachers improve our pronunciations so that our students can be exposed to the correct pronunciations of the English words. On the other hand, the students should train their ears more frequently. The reading comprehension and the listening comprehension are two different processes in that they come to the students' brain through different channels: the former through the visual channel while the latter through the audio one. In this sense, those who are good at reading comprehension are not necessarily good at listening comprehension. To overcome this problem, the students should adjust to various speeches, for example, the American English, British English, black English or the Indian English and so on. Otherwise, they will spend a lot of time and efforts adapting to the speakers' pronunciations. This is also why most of their mistakes appear in the first two sentences. Accordingly, they cannot understand or jot down the other sentences since there is no semantic context.

B. Some hints on spelling. Even if some of the students can understand the essay, they still cannot write the essay down. As far as the reason is concerned, it can be viewed from the following aspects: first of all, it is because the students have seldom had this kind of practice. Therefore, their spellings undergo the controlled 
processes, instead of the automatic processes. From this sense, we suggest that the students take notes while they are practicing their listening, since this will help them to recall the program later on, and it will also train their ability of short-hand. Most important of all, it will help them keep longer the trace of the information in their minds so that they can have a better listening comprehension. Secondly, they have not made the best use of working memory. We know that during the process of dictation, the working memory is in a contradicting state. On the one hand, it will try to store as much information as possible in their minds. On the other hand, it will try to process or understand the material. But the problem is that the storage of the working memory is limited, hence it is quite burdensome for it to work efficiently. For some students, they try to memorize every word in the passage at the cost of the understanding of it without the intention to combine them logically. This adds much burden to their working memory and brain. Finally, their brain is full so it cannot hold the previous information and the results of dictation is severely affected. For others, they simply try to follow the material quickly without leaving anything in their mind. They can only memorize the meaning of the last sentence, so when the tape comes to the end, their memory of the passage also comes to the end. The suggestion for them is that they need balance the two aspects, that is to say, they should hold as much information in their mind while they try to understand the essay. Thirdly, how to memorize much more information? They should pay more attention to the unit of their information storage. Usually, students choose to store the information word by word. Yet, according to psychological study, the temporary store can hold only $7 \pm 2$ items. If the students only try to understand the essay word by word, they can only memorize 5 to 9 words each time. If they want to have a better memory of the essay, they need to change the unit of their storage. In other words, they can increase their retention by grouping individual pieces of information into larger units, a process known as chunking. We hope that students can enlarge their information unit -not by words but by meaningful chunk. In this sense, the phrase "in front of" does not have 3 units, but 1 unit since there is only one meaning implied. Fourthly, when they jot down the sentences, we also wish that they could use the phonemic restoration, for we find some students can only write down the beginning words in the sentences. Here, the suggestion is that they should take the key word strategy. If they can take the words down, that means they have got the propositions of the sentence. With the help of the semantic and syntactic factors, they can find the correct words back quite easily. For example, in the following sentences, the students can find the missing words back quickly: "It was found that the *eel was on axle/shoe/orange/table." The missing words for each of the sentence are: wheel, heel, peel, meal, because according to the meanings and structures of the sentences, only those words can suit the specific situations.

C. The meaning of the sentences should play the key part in the course of dictation since it connects both the bottom-up and the top-down process. It is also the process that connects the students' permanent memory and their written work. In practice, we can find the following problems: first, some students only pay attention to retaining the exact or verbatim wording of a sentence instead of its meaning. If this is the case, those students have not made the best use of the context. What they are doing is equal to the situation where they are trying to take down the sentences at random order. So the idealized situation is that they should try to get the memory of meaning instead of the surface form. Second, the meaning of the sentence can be completely changed because of the students' vocabulary. When they try to get the words out of their mental lexicon, there is the effect of economy policy, which means they try to select the most frequently used words, in most cases, the high frequency words, to match a certain pronunciation. For example, in 1997, one sentence in the dictation passage is "The legal ages for marriage vary from state to state." Many students misspelled the word "vary" as "very" because comparatively speaking, "very" is a much more frequently used word than "vary". Third, the meaning of a sentence should also be examined in terms of propositions instead of words as the meaning is usually of greater interest, more processing resources are devoted to the meaning (which persists for a period of time) than to the surface form (which fades over a briefer interval). But because meaning is stored in the brain by means of propositions, while listening to a piece of passage, students should try to catch the proposition(s) of the sentence, which is usually more concise than the sentence itself. For example, the sentence "It was Harry who was hit by George" can be written as "Hit (George, Harry)" by using the rule of proposition. Then by applying the grammatical rules and semantic and syntactic rules, the surface structure can be restored. On the contrary, if the students intend to retell the sentence word by word, the burden for the working memory is quite heavy since there are altogether eight units in terms of words in the sentence, yet there are only three units by means of proposition. In this way, the meaning of the sentences can be simplified.

\section{Conclusion}

As can be seen, listening plays an important role in students' learning of English since it ranks the first among the five basic skills: listening, speaking, reading, writing, and translating. According to linguists, $45 \%$ of speakers' time is spent listening to others' speech (Zhou, 2003, p. 205). Most of their information comes from 
their listening; therefore, dictation is a very good way to test their receptive ability. From the perspective of psycholinguistics, there are many effective theories and methodologies that can be used to improve the students' performance in taking the exam as mentioned above. When used properly, it can also help the users of language to achieve successful communications in their daily life.

\section{References}

Carroll, D. W. (2000). Psychology of Language. Beijing: Foreign Language Teaching and Research Press.

Chen, H. S. (2001). A New Guide to TEM-4. Shanghai: Shanghai Foreign Language Education Press.

Han, W. (2004). An Analysis of Features of Dictation in TEM-4 and Strategies to Improve. A Journal of Gannan Teachers' College, $\quad 1, \quad 85-89 . \quad$ Retrieved from http://www.cnki.net/KCMS/detail/detail.aspx?QueryID=11\&CurRec=8\&dbcode=CJFQ\&dbname=CJFD03 $05 \&$ filename $=$ GNSY200401035\&urlid $=\& y x=\& u i d=$ WEEvREcwSIJHSldSdnQ1ZmM5QTIBSGdYUmpSV WxPLzNpZzRKK09KcTBoZ25EZ3c1S0VvQ3p1NTQ3N3ZZQklnPQ==\&v=MjMyODFpUFlkN0c0SHR YTXJvOUdZWVI4ZVgxTHV4WVM3RGgxVDNxVHJXTTFGckNVUkxtZllPZHNGeW5uVmJyQkk=

Shang, Y. Z. (2001). To Develop Students' Power of Thinking in the Teaching of Listening Comprehension. Foreign Language Teaching Through Technologies, 4, 102-105. Retrieved from http://www.cnki.net/KCMS/detail/detail.aspx?QueryID $=0 \&$ CurRec $=1 \&$ dbcode $=$ CJFQ \&dbname $=$ CJFDHIS \& filename $=$ WYDH200104001\&urlid $=\& y x=\& u i d=$ WEEvREcwSIJHSldSdnQ0UHBUTE1XQmppdkVTTE NsSjRIRjlBZUtVandybFVvRVV6M31FbjlrOXAxTVhEK2FrPQ==

Sheng, L. P. (2003). Error Analysis in TEM-4 Dictation. Journal of Anhui University of Technology (Sociel Sciences), 3, 54-56. Retrieved from http://www.cnki.net/KCMS/detail/detail.aspx?QueryID=24\&CurRec=4\&dbcode=CJFQ\&dbname=CJFD03

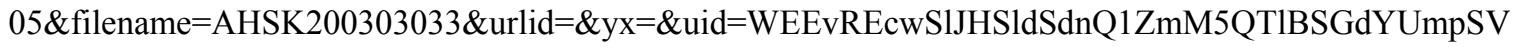
WxPLzNpZzRKK09KcTBoZ25EZ3c1S0VvQ3p1NTQ3N3ZZQklnPQ==\&v=MDE4Nj10TE1ySTlHWjRS OGVYMUx1eFITNORoMVQzcVRyV00xRnJDVVJMbWZZT2RzRnlublc3ektKQ1hZWmJHNEg=

Team of Revising the Syllabus for TEM4. (2004). Syllabus for TEM4. Shanghai: Shanghai Foreign Language Education Press.

Wang, C. M. (1990). Applied Sycholingusitics. Changsha: Hunan Education Press.

Xiao, X. Y. (2001). The role of phonological representations in orthographical lexical access. Foreign Language Teaching and Research, 6, 33-37. Retrieved from http://www.cnki.net/KCMS/detail/detail.aspx?QueryID=5\&CurRec=1\&dbcode=CJFQ\&dbname=CJFD990 2\&filename=WJYY200106005\&urlid=\&yx=\&uid=WEEvREcwSIJHSIdSdnQ1ZmM5QTIBSGdYUmpSV WxPLzNpZzRKK09KcTBoZ25EZ3c1S0VvQ3p1NTQ3N3ZZQklnPQ==\&v=MDUwMDIxTHV4WVM3R GgxVDNxVHJXTTFGckNVUkxtZIIPZHNGeW5uVTdyT01pZINkN0c0SHRETXFZOUZZWVI4ZVg=

Yang, M. Z. (2003). On Impact of English Language Learners' Language Competence Through Dictation. Modern Foreign Languages, 3, 28-32. Retrieved July 10, 2013, from http://www.cnki.net/KCMS/detail/detail.aspx?QueryID=29\&CurRec=2\&dbcode=CJFQ\&dbname=CJFD03

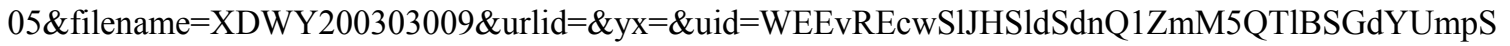
VWxPLzNpZzRKK09KcTBoZ25EZ3c1S0VvQ3p1NTQ3N3ZZQklnPQ==\&v=Mjc0MzJyST1GYllSOGV YMUx1eFITN0RoMVQzcVRyV00xRnJDVVJMbWZZT2RzRnluZ1VyckJQU25jZDdHNEh0TE0=

Zhang, Y. L. (1998). Language Testing of the English Language. Shanghai: Shanghai Foreign Language Education Press.

Zhou, S. (2003). A Study on Applied Language Test. Chengdu: Sichuan University Press.

\section{Copyrights}

Copyright for this article is retained by the author(s), with first publication rights granted to the journal.

This is an open-access article distributed under the terms and conditions of the Creative Commons Attribution license (http://creativecommons.org/licenses/by/3.0/). 